\title{
Factors Associated with Advanced Disease Stage at Diagnosis in a Study of Patients with Newly Diagnosed Breast Cancer
}

\author{
Popoola Abiodun ${ }^{1, *}$, Sowunmi Anthonia ${ }^{2}$, Omodele Foluso ${ }^{3}$, Odedina Stella ${ }^{4}$ \\ ${ }^{1}$ Oncology Unit, Department of Radiology, Lagos State University College of Medicine, Ikeja, Nigeria \\ ${ }^{2}$ Department of Radiotherapy, Lagos University Teaching Hospital, Idiaraba, Nigeria \\ ${ }^{3}$ Department of Surgery, Lagos State University Teaching Hospital, Ikeja, Nigeria \\ ${ }^{4}$ West African Breast Cancer Study Unit, Lagos State University College of Medicine, Ikeja, Nigeria
}

\section{Email address:}

pabiodun2001@yahoo.com (P. Abiodun), toniasow@yahoo.com (S. Anthonia), omodelefolusho@yahoo.com (O. Folusho), stellakinleye@yahoo.com (O. Stella)

*Corresponding author

\section{To cite this article:}

Popoola Abiodun, Sowunmi Anthonia, Omodele Foluso, Odedina Stella. Factors Associated with Advanced Disease Stage at Diagnosis in a Study of Patients with Newly Diagnosed Breast Cancer. Journal of Cancer Treatment and Research. Vol. 6, No. 2, 2018 , pp. $19-24$. doi: $10.11648 /$ j.jctr.20180602.12

Received: June 25, 2018; Accepted: July 26, 2018; Published: August 1, 2018

\begin{abstract}
The objectives of this study is to identify potential predictors of long delay and to examine the association between breast cancer patient delay and stage at diagnosis. Breast cancer stage represents an important prognostic factor and advanced stage is associated with decreased time of disease-free survival and increased mortality rates. Thus, reducing these delays is believed to be of high importance. For the period of this study, February 2017 to January 2018, 171 patients were interviewed, Predictors of breast cancer stage at time of diagnosis was determined by bivariate analysis using ordinal logistic regression. The relationship between each of the independent variables with breast cancer stage was determined. A greater percentage of the study participants were below 50 years of age $(52 \%)$ and the mean \pm SD age was $49.5 \pm 11.3$ years. The percentage of premenopausal women among the study population was $48.2 \%$ while postmenopausal women was $51.8 \%$. BMI of $<25$ is $32 \%, 25-29$ is $47 \%$ while $>30$ was 20 . The odds for advanced breast cancer stage is 2.75 for women who had $1-2$ months diagnosis delay compared to women who had below 1 month delay. Those with $>2$ months diagnosis delay also had higher odds compared to those who had below 1 month delay $(\mathrm{OR}=2.05,95 \% \mathrm{CI}=1.04-4.06)$. The final ordinal logistic model revealed that variables that remained significant were having moderately differentiated tumour histology grade $(\mathrm{aOR}=$ $0.11,95 \% \mathrm{CI}=0.04-0.28)$, well differentiated tumour histology grade $(\mathrm{aOR}=0.35,95 \% \mathrm{CI}=0.13-0.92)$ and bra cup size $\mathrm{C}$ $(\mathrm{aOR}=0.41,95 \% \mathrm{CI}=0.17-0.98)$. Improved screening, awareness and education programs are required by the health care professionals and health policy makers in order to promote early detection of breast cancer to avoid diagnosis at advanced stages.
\end{abstract}

Keywords: Delayed Diagnosis, Advanced Stage, Breast Cancer

\section{Introduction}

The incidence of breast cancer in developing countries including Nigeria is lower compared to developed countries, with 31.3 new cases per 100000 women in comparison to the 74.1 new cases per 100000 observed in developed regions. Nevertheless, the mortality rates are actually higher in developing countries [1]. The reasons adduced for the differences in mortality rates include advanced stages at presentation, worse biologic behavior, poor treatment facilities and poor patient acceptance of recommended treatments which have been linked to ignorance, superstition, self denial, fear of mastectomy and unavailability of treatment facilities [2].

More than $70 \%$ of breast cancer patients in developed 
countries are diagnosed at stages I and II, whereas in low and middle-income countries, only $20-60 \%$ of patients are diagnosed in early stages of the disease: Breast cancer stage represents an important prognostic factor and advanced stage is associated with decreased time of disease-free survival and increased mortality rates. Thus, reducing these delays is believed to be of high importance. The Nonattribution of symptoms to cancer, fear of the disease and treatment and low educational level were the most frequent causes of patient delay [3].

Data on the impact of delays in diagnosis on breast cancer outcomes are mixed. In a meta-analysis by Richards and colleagues of $>25,000$ women, those who experienced a delay of at least 3 months between the onset of symptoms and treatment for breast cancer were $12 \%$ less likely to be alive 5 years later [4]. Breast cancer total delay has been defined as more than three months between symptom discovery and the beginning of cancer treatment and has been classified in two types: patient delay and provider delay Patient-related delay time (PDT), was defined as the time between the onset of first symptoms and the first medical visit and the most accepted threshold to establish it is three months [5].

The objectives of this study is to identify potential predictors of long delay and to examine the association between breast cancer patient delay and stage at diagnosis.

\section{Methodology}

The study was carried out at the Oncology clinic of the Lagos State University Teaching Hospital, Ikeja, Lagos, Nigeria. The hospital is one of the two teaching hospitals in the State comprising of several departments such as Surgery, Medicine, Paediatrics, Obstetrics \& Gynaecology, Radiology, etc.

\subsection{Study Design}

This is a descriptive cross sectional study conducted among breast cancer patients of Lagos State University Teaching Hospital.

\subsubsection{Inclusion Criteria}

1. Patients of $18 \mathrm{yrs}$ and above

2. Histological confirmation of breast cancer

\subsubsection{Exclusion Criteria}

1. Age below $18 y$ rs

2. Patients with psychiatric illness

\subsection{Sampling Method}

A total of 171 histologically diagnosed advanced breast cancer patients attending oncology clinic between February 2017 and January 2018 were recruited

\subsection{Data Collection}

This was conducted with the aid of an interviewer administered semi structured questionnaire containing close ended and a few open ended questions (which included the bio data and assessment of their knowledge \& practice of breast cancer screening.

\subsection{Data Analysis}

Data entry was done using excel and data analysis performed using stata version 14. Variables were summarized using frequency tables, means and standard deviations. Breast cancer stage at time of diagnosis was used as outcome (dependent) variable. Stage IIa was considered as the reference stage, while stages IIb, III, IV were advanced stages. Independent variables were age group, menopause status, co-morbidities, family history, education, poverty index, mammogram done in last 5 years, Breast Self Examination practise, method of detection, BMI, bra cup size, delay in diagnosis (time) and tumour histology grade.

Bivariate analysis using ordinal logistic regression was conducted to determine predictors of breast cancer stage at time of diagnosis. The relationship between each of the above independent variables with breast cancer stage was determined. Variables significant at $\mathrm{p}<0.05$ in bivariate analysis were entered into the final ordinal logistic model (Multiple logistic regression). Level of statistical significance was at $\mathrm{p}<0.05$.

\section{Result}

For the period of this study, February 2017 to January 2018, 171 patients were interviewed. A greater percentage of the study participants were below 50 years of age $(52 \%)$ and the mean \pm SD age was $49.5 \pm 11.3$ years. The percentage of premenopausal women among the study population was $48.2 \%$ while postmenopausal women was $51.8 \%$. BMI of $<25$ is $32 \%, 25-29$ is $47 \%$ while $>30$ was $20 \%$ (table 1 ).

Married women among the study participants accounted for $76.5 \%$, divorced women constituted $1.8 \%$, single women were $5.3 \%$ and widow were $16.5 \%$. Percentage of women who attained primary education was $14.6 \%$, secondary education $45.5 \%$ while tertiary was $39.8 \%$ (table 1 ). A greater percentage of the participants were in the low and middle income group (59.9\% and 38.3\% respectively) (table 1). Majority (94\%) had no family history of breast cancer (table 1).

Table 1. Characteristics of study participants $(N=171)$.

\begin{tabular}{lll}
\hline Variables & Frequencies (n) & Percentages (\%) \\
\hline Age group (years) & & \\
$20-39$ & 30 & 17.5 \\
$40-49$ & 59 & 34.5 \\
$50-54$ & 32 & 18.7 \\
$>54$ & 50 & 29.2 \\
Menopausal Status* $\mathrm{N}=168$ & & \\
Premenopausal & 81 & 48.2 \\
Postmenopausal & 87 & 51.8 \\
BMI kg/m ${ }^{2} \mathrm{~N}=165$ & & \\
$<25$ & 53 & 32.1 \\
$25-29.9$ & 79 & 47.9 \\
$>30$ & 33 & 20.0 \\
Co-morbidities* $\mathrm{N}=169$ & & \\
None & 116 & 68.6 \\
1 or more & 53 & 31.4 \\
Marital Status* $\mathrm{N}=170$ & & \\
\hline
\end{tabular}




\begin{tabular}{lll}
\hline Variables & Frequencies (n) & Percentages (\%) \\
\hline Never married & 9 & 5.3 \\
Married & 130 & 76.5 \\
Divorced & 3 & 1.8 \\
Widowed & 28 & 16.5 \\
Education & & \\
None/primary & 25 & 14.6 \\
Secondary & 78 & 45.6 \\
Degree & 68 & 39.8 \\
Poverty Index* N=167 & & \\
Low income & 100 & 59.9 \\
Middle income & 64 & 38.3 \\
High income & 3 & 1.8 \\
Smoking & & \\
No & 171 & 100.0 \\
Yes & 0 & 0.0 \\
Family History & & \\
No & 161 & 94.2 \\
Yes & 10 & 5.9 \\
\hline
\end{tabular}

* missing $\mathrm{N} \neq 171$.

Of the 171 patients seen, 157 had breast cancer stage graded at diagnosis. Approximately $19.8 \%$ had stage IIa, $14 \%$ were stage IIb, $56 \%$ stage III, and 10.2 stage IV (figure 1). Majority of the patients had poorly differentiated tumours $(43.7 \%)$ while moderately and well differentiated tumours were $34 \%$ and $22.7 \%$ respectively (table 2 ). From the participants, $49 \%$ had delayed diagnosis of $>2$ months, $18.6 \%$ of between $1-2$ months and $32.3 \%$ of less than 1 month. A larger percentage of $93.8 \%$ detected the tumour by themselves. Among other reasons financial constraint is one of the greatest factor that contributed to advanced stage at diagnosis (table 2).

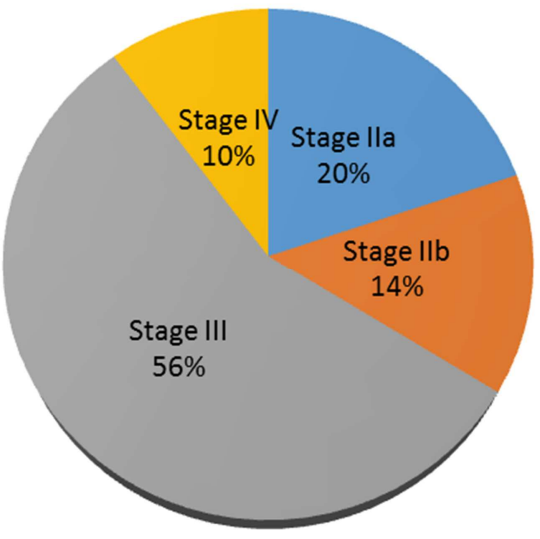

Figure 1. Proportion of breast cancer stages at diagnosis $(N=157)$.

Table 2. Other characteristics of study participants $(N=171)$.

\begin{tabular}{|c|c|c|}
\hline Characteristics & Frequencies (n) & Percentages (\%) \\
\hline \multicolumn{3}{|c|}{ Mammogram done in last 5years* $\mathrm{N}=168$} \\
\hline None & 86 & 51.2 \\
\hline $1-2$ & 71 & 42.3 \\
\hline$>2$ & 11 & 6.6 \\
\hline \multicolumn{3}{|c|}{ Breast Self Examination* N=169 } \\
\hline None & 60 & 35.5 \\
\hline$<12$ in a year & 79 & 46.8 \\
\hline$\geq 12$ in a year & 30 & 17.8 \\
\hline \multicolumn{3}{|l|}{ Method of detection* N=169 } \\
\hline Self detection & 158 & 93.5 \\
\hline Clinical Breast Examination & 4 & 2.4 \\
\hline Mammogram & 3 & 1.8 \\
\hline Others & 4 & 2.4 \\
\hline \multicolumn{3}{|l|}{ Bra cup-size* $\mathrm{N}=165$} \\
\hline$A$ and $B$ & 43 & 26.1 \\
\hline $\mathrm{C}$ & 76 & 46.1 \\
\hline $\mathrm{D}$ & 46 & 27.9 \\
\hline \multicolumn{3}{|c|}{ Delay in diagnosis (months) $* \mathrm{~N}=167$} \\
\hline$<1$ & 54 & 32.3 \\
\hline $1-2$ & 31 & 18.6 \\
\hline$>2$ & 82 & 49.1 \\
\hline \multicolumn{3}{|c|}{ Tumour histology grade* $\mathrm{N}=141$} \\
\hline Poorly differentiated & 61 & 43.3 \\
\hline Moderately differentiated & 48 & 34.0 \\
\hline Well differentiated & 32 & 22.7 \\
\hline \multicolumn{3}{|l|}{ Molecular Subtypes* N=71 } \\
\hline Luminal A & 14 & 14.1 \\
\hline Luminal B & 2 & 2.0 \\
\hline HER2 enriched & 9 & 9.1 \\
\hline Triple negative & 29 & 29.3 \\
\hline ER+, PR-, HER+ & 2 & 2.0 \\
\hline ER+, PR-, HER- & 5 & 5.1 \\
\hline $\mathrm{ER}+, \mathrm{PR}+$ & 14 & 14.2 \\
\hline ER+, PR-, or ER-, PR- & 6 & 6.1 \\
\hline ER-, PR+, HER+ & 2 & 2.1 \\
\hline ER-, PR- & 16 & 16.2 \\
\hline
\end{tabular}


Table 3 shows the bivariate analysis of independent variables with breast cancer stage at diagnosis using ordered logistic regression. The odds of having cancer stage IV, III, IIb increases as bra cup size becomes larger, in addition the odds of having stage IV, III, IIb versus stage II is lower for women who had bra size $\mathrm{C}$ compared to women who had size $\mathrm{A}$ or $\mathrm{B}(\mathrm{OR}=0.66,95 \% \mathrm{CI}=0.29-1.52)$. Women who had moderately differentiated status had lower odds of having stage IV, III, IIb compared to women who had poorly differentiated status $(\mathrm{OR}=0.09,95 \% \mathrm{CI}=0.04-0.23)$. Those with well differentiated status also had lower odds compared to those who had poorly differentiated status (OR $=0.35,95 \% \mathrm{CI}=0.14-0.88$ ) (table 3 ).

The odds for advanced breast cancer stage is 2.75 for women who had 1-2 months diagnosis delay compared to women who had below 1 month delay. Those with $>2$ months diagnosis delay also had higher odds compared to those who had below 1 month delay $(\mathrm{OR}=2.05,95 \% \mathrm{CI}=$ $1.04-4.06$ ) (table 3). No significant association was found between advanced breast cancer stage and other independent variables studied (table 3).

Table 3. Association between Breast Cancer stages and variables studied using ordered logistic regression.

\begin{tabular}{ll}
\hline Independent variables & Crude OR (95\% C. I.) \\
\hline Age group (years) & $1(\mathrm{ref})$ \\
$20-39$ & $1.51(0.59-3.81)$ \\
$40-49$ & $1.62(0.57-4.62)$ \\
$50-54$ & $1.08(0.42-2.83)$ \\
$>54$ & $1(\mathrm{ref})$ \\
Menopausal Status & $0.68(0.37-1.26)$ \\
Premenopausal & \\
Postmenopausal & $1(\mathrm{ref})$ \\
Marital Status & $0.33(0.06-1.74)$ \\
Never married & $2.79(0.19-40.63)$ \\
Married & $1.13(0.19-6.63)$ \\
Divorced & \\
Widowed & $1(\mathrm{ref})$ \\
Co-morbidities & $0.67(0.35-1.29)$ \\
None & \\
1 or more & $1(\mathrm{ref})$ \\
Family History & $1.83(0.53-6.33)$ \\
No & \\
Yes & $1(\mathrm{ref})$ \\
Education & $1.46(0.56-3.81)$ \\
None/primary & $1.28(0.48-3.39)$ \\
Secondary & \\
Degree & $1(\mathrm{ref})$ \\
Poverty Index & $0.63(0.33-1.19)$ \\
Low income & $0.42(0.07-2.59)$ \\
Middle income & $1(\mathrm{ref})$ \\
High income & $1.01(0.54-1.89)$ \\
Mammogram done in last 5years & $1.21(0.36-4.08)$ \\
None & $1(\mathrm{ref})$ \\
$1-2$ & $1.35(0.69-2.64)$ \\
$>2$ & $1.64(0.66-4.10)$ \\
Breast Self Examination & \\
None & $1(\mathrm{ref})$ \\
$<12$ in a year & \\
$\geq 12$ in a year & \\
Method of detection & \\
Self detection & \\
\hline & \\
\hline
\end{tabular}

\begin{tabular}{ll}
\hline Independent variables & Crude OR (95\% C. I.) \\
\hline Clinical Breast Examination & $2.54(0.24-27.48)$ \\
Mammogram & $0.67(0.07-6.06)$ \\
Others & $1.02(0.14-7.44)$ \\
BMI kg/m & \\
$<25$ & $1(\mathrm{ref})$ \\
$25-29.9$ & $0.92(0.46-1.87)$ \\
$>30$ & $1.27(0.53-3.02)$ \\
Bra cup-size & \\
A and B & $1($ ref $)$ \\
C & $0.37(0.17-0.79)$ \\
D & $0.66(0.29-1.52)^{* *}$ \\
Delay in diagnosis (months) & \\
$<1$ & $1(\mathrm{ref})$ \\
$1-2$ & $2.75(1.08-7.03)^{* *}$ \\
$>2$ & $2.05(1.04-4.06)^{* *}$ \\
Tumour histology grade* $\mathrm{N}=141$ & \\
Poorly differentiated & $1(\mathrm{ref})$ \\
Moderately differentiated & $0.09(0.043-0.23)^{* *}$ \\
Well differentiated & $0.35(0.14-0.88)^{* *}$ \\
\hline
\end{tabular}

$* *$ significant at $\mathrm{p}=0.05$.

The final ordinal logistic model (Multiple logistic regression) is shown on table 4. Variables that remained significant were having moderately differentiated tumour histology grade $(\mathrm{aOR}=0.11,95 \% \mathrm{CI}=0.04-0.28)$, well differentiated tumour histology grade $(\mathrm{aOR}=0.35,95 \% \mathrm{CI}$ $=0.13-0.92)$ and bra cup size $\mathrm{C}(\mathrm{aOR}=0.41,95 \% \mathrm{CI}=$ $0.17-0.98)$.

Table 4. Multiple logistic regression showing predictors of advanced breast cancer staging.

\begin{tabular}{llll}
\hline Significant variables & $\begin{array}{l}\text { Adjusted Odds } \\
\text { ratio (aOR) }\end{array}$ & $\begin{array}{l}\text { 95\% Confidence } \\
\text { Interval }\end{array}$ & p-Values \\
\hline $\begin{array}{l}\text { Delay in diagnosis } \\
\text { (months) }\end{array}$ & & & \\
$<1$ & $1(\mathrm{ref})$ & & \\
$1-2$ & 2.73 & $0.93-7.96$ & 0.067 \\
$>3$ & 1.61 & $00.74-3.50$ & 0.233 \\
$\begin{array}{l}\text { Bra cup-size } \\
\text { A and B }\end{array}$ & $1(\mathrm{ref})$ & & \\
C & 0.41 & $0.17-0.98$ & $0.045^{* *}$ \\
D & 0.67 & $0.26-1.79$ & 0.418 \\
Tumour histology & & & \\
grade & & & \\
Poorly differentiated & $1(\mathrm{ref})$ & $0.04-0.28$ & $<0.001^{* *}$ \\
$\begin{array}{l}\text { Moderately } \\
\text { differentiated }\end{array}$ & 0.11 & $0.13-0.92$ & $0.033^{* *}$ \\
\hline Well differentiated & 0.35 & & \\
\hline
\end{tabular}

$* *$ significant at $\mathrm{p}=0.05$.

\section{Discussion}

There is a higher odds of having stage IV, III, IIb versus stage II among women 40-49 years of age compared to women below 40 years of age. Report from various ethnic populations have reported the demographic profile of breast cancer especially from the Western and Northern parts of the country and described the mean age at presentation of breast cancer as 42 years and that $69 \%$ of these patients were premenopausal. 
Older women tended to consider their symptoms as temporary more often than middle aged or younger women and tend to wait longer than younger women before presenting their symptoms to a physician, they may also be unaware of the fact that they are at higher risk compared to younger women leading to delayed diagnosis. Fatalism, e.g. a sense that one has lived long enough, might be another reason for the higher proportion of patient delay among older breast cancer patients [6].

Even though not statistically significant, married women in this study had lower odds for advanced staged breast cancer compared to unmarried women While lower SES has been associated with late-stage breast cancer diagnosis in several studies, the only significant effect in the study carried out by Joseph Lipscomb et al was that single women were generally at higher risk to advanced stage than married women, whereas Popoola etal discovered that emotional support is most beneficial in the adjustment of women with breast cancer, generating opportunities for them to express feelings and favoring treatment adherence and spouse has been found out the most important emotional support and the main source of instrumental support [7-8].

Respondents that reported a history of one or more family with breast cancer had higher odds of advanced staged breast cancer compared to those that reported none. Similar to this is the observation by Kathryn etal, they believe having a relevant family history should trigger more rapid evaluation and diagnosis of a self-detected breast complaint, however Kathryn et al felt their finding may be spurious, or it could be the result of recall bias in a population that may have more baseline anxiety based on lived experience and family history. Another explanation they gave is that some women who have first-degree relatives with breast or ovarian cancer may be hypervigilant, presenting so quickly for medical attention that clinicians wait for a few menstrual cycles before they perform definitive diagnostic testing [9]

The study found higher odds of advanced staged breast cancer for women with secondary education compared to women with none or primary however no statistical association was found. Some other studies however reported significant association between early detection of breast cancer and higher level of education ie, those who completed high school/ any tertiary education were at lower risk for advanced -stage presentation than those who had informal or only primary school education [10-11].

Lower odds of advanced breast cancer stage was found for women with middle income compared to women with lower income. Low socio-economic status were found to be the factors associated with a delayed consultation because it has been discovered that women with less financial resources are more likely not to seek care in health facilities leading to delay in several studies [12, 13-14].

No association was found between women who had done 1-2 mammogram in past 5 years compared to women who did not. This may be due to the fact that mammogram screening should be done yearly. Screening mammography has been consistently associated with earlier-stage detection of breast cancer, both in clinical trials and in day-to-day practice. Utilisation of this screening examination reflects attitude towards screening programmes and is likely to be a good marker for health behaviour and general health care utilisation. Thus it is not surprising to observe that women who attend the general health check-up screening examination are more likely to present their breast symptoms in a timely manner to a physician than those who do not attend these screening examinations. Although women who undergo breast cancer screening tend to be more health conscious, they might feel less worried about some vague alterations of the breast if the last mammography or clinical examination had been normal. Other studies show no clear evidence of an association between lack of breast self examination and patient delay [6].

Patient delay tended to be slightly less common among women who reported at least monthly breast self examination or women who underwent professional breast cancer screening during the past 5 years but the differences were small and not statistically significant. Practicing breast self-examination was also discovered to be associated with a shorter patient delayed time in a study carried out by Jacek Jassem et al. In this study, the odds of having advanced stage breast cancer was higher for women who had it detected via CBE compared to women who detected by self $[6,15]$.

A $25 \%$ odds of having advanced breast cancer stage was found among women with $>30$ BMI compared to women with $<25 \mathrm{BMI}$ as well as odds of increased stage as Bra cup size becomes larger from Bra cup size $\mathrm{C}(\mathrm{OR}=0.37)$ to $\mathrm{Bra}$ cup size $\mathrm{D}(\mathrm{OR}=0.66)$.

Among variables describing health characteristics, obesity or bra size as a surrogate showed the strongest association with diagnosis of advanced stage breast cancer, this association could be due to a delay in diagnosis among obese women. Overweight/obese women have larger breasts, and thus tumor detection may be more difficult in these women simply because tumors are more difficult to palpate in larger breasts [16].

A significant association was found between tumour histologic grade and breast cancer stage in this study, and it remained significant even after adjusting for other significant variables from bivariate analysis. Women who had moderately differentiated histological status had lower odds for advanced breast cancer stage compared to women with poorly differentiated histological status. According to Lipscomb etal advanced stage was positively related to whether the tumor was HER2 Type, the tumor grade was not well-differentiated, or else poorly undifferentiated. These tumours are aggressive and tend to metastasise rapidly as revealed by Popoola etal in their study where all poorly differentiated breast cancer metastsised after two year follow up [17-18].

At bivariate analysis, significant association was found between diagnosis delay (months) and breast cancer stage. The odds of having advanced breast cancer was higher for women who had 1-2 months diagnosis delay compared to women who had below 1 month delay. From a study carried 
out by---, Late stage breast cancer was found in greater percentage of all patients and it tended to be more frequent among women with patient delay $>3$ months than among women who consulted a doctor within 1 month after onset of symptoms [6]. Longer patient-related delay times were associated with patients perception regarding the symptoms to be harmless and temporary, due to poor breast cancer awareness, ignorance, superstition, self-denial, fear of mastectomy, these factors make them overlook the importance of these warning signs and symptoms of breast cancer, leading to progression of the disease and even proving to be fatal in late stages.

\section{Conclusion}

Delay in diagnosis and treatment of breast cancer remains a serious problem. Improved screening, awareness and education programs are required by the health care professionals and health policy makers in order to promote early detection for common cancer types such as breast so that a substantial proportion with breast cancer symptoms would present to a doctor within 1 month and avoid diagnosis at advanced stages.

\section{References}

[1] Ferlay J, Soerjomataram I, Ervik M, Dikshit R, Eser S, Mathers C, Rebelo M, Parkin DM, Forman D Bray F.(2013) Globocan 2012 v1. 0. Cancer Incidence and Mortality Worldwide. IARC Cancer Base No. 11 [internet] Lyon, France: International Agency for Research on Cancer; 2013.

[2] Popoola. A. O, Wright K. O, Igwilo A. I, Sowunmi A, Kuyinu Y. A (2011) Literacy and Breast Cancer Diagnosis and Treatment among Patients in a Tertiary Health Institution of Lagos Nigeria; IOSR Journal of Dental and Medical Sciences (IOSR-JDMS); Volume 5, Issue 4, PP 49-54.

[3] Unger-Saldaña K, (2014), Challenges to the early diagnosis and treatment of breast cancer in developing countries.) World Journal Clinical Oncology. 2014 Aug 10; 5(3):465-77. doi: 10. 5306/wjco. v5. i3. 465.

[4] Richards MA, Westcombe AM, Love SB, Littlejohns P, Ramirez AJ. (1999) Influence of delay on survival in patients with breast cancer: a systematic review. Lancet. 1999; 353: 1119-1126.

[5] Unger-Saldaña K, Infante-Castañeda C. (2009) Delay of medical care for symptomatic breast cancer: a literature review. Salud Publica Mex. 2009; 51 Suppl 2:s270-s285. [PubMed]

[6] T Stürmer, C Stegmaier, H Ziegler, G Dhom (2002), Patient delay and stage of diagnosis among breast cancer patients in Germany - a population based study, British Journal of Cancer Br J Cancer. 2002 Apr 8; 86(7): 1034-1040. doi: 10.1038/sj.bjc.6600209

[7] Lipscomb J, Steven T. F, Trentham-Dietz A, Kimmick G, Xiao-Cheng W, Morris C R, Zhang K, Smith R A, Anderson
R T and Sabatino S A. (2016) What Predicts an AdvancedStage Diagnosis of Breast Cancer? Sorting Out the Influence of Method of Detection, Access to Care, and Biologic Factors Cancer Epidemiology, Biomarkers \& Prevention January 27, 2016; DOI: 10. 1158/1055-9965. EPI-15-0225.

[8] Popoola A. O., Makanjuola S., Sowunmi O., Igwilo A., Oludara M., Ibrahim N., Omodele F.(2015) Level of Adherence to Cytotoxic Drugs by Breast Cancer Patients' in Lagos State University Teaching Hospital. Journal of Cancer Therapy 6: 383-389 -

ht9\\tp://dx.doi.org/10.4236/jct.2015.64041

[9] Kathryn J. Ruddy; Shari Gelber; Rulla M. Tamimi; Lidia Schapira; Steven E. Come;Meghan E. Meyer; Eric P. Winer; and Ann H. Partridge, Breast Cancer Presentation and Diagnostic Delays in Young Women https://onlinelibrary.wiley.com/doi/full/10.1002/cncr.28287

[10] Literacy and Breast Cancer Diagnosis and Treatment among Patients in a Tertiary Health Institution of Lagos Nigeria; IOSR Journal of Dental and Medical Sciences (IOSR-JDMS); Volume 5, Issue 4, PP 49-54.

[11] Maureen Joffe, Oluwatosin Ayeni, Shane Anthony Norris, Valerie,(2, Feb, 2018), Barriers to early presentation of breast cancer among women in Soweto, South Africa https://doi.org/10.1371/journal.pone.0192071

[12] Brzozowska, A., Duma, D. and Mazurkiewicz, T. (2014) Reasons for Delay in Treatment of Breast Cancer Detected Due to Breast Self-Examination in Women from the Lubelskie Region. Ginekologia Polska, 85, 14-17. https://doi.org/10.17772/gp/1684

[13] Norsa'adah, B., Rampal, K. G. and Rahmah, M. A. (2011) Diagnosis Delay of Breast Cancer and Its Associated Factors in Malaysian Women. BMC Cancer, 11, https://doi.org/10.1186/1471-2407-11-141

[14] Ruddy K J, Gelber S, Tamimi R S, Schapira L, Come S E, Meyer M E; Winer E P; and Partridge A H, Breast Cancer Presentation and Diagnostic Delays in Young Women.

[15] Jassem J, Ozmen V, Bacanu F, Drobniene M, Eglitis J, Lakshmaiah K C, Kahan Z, Mardiak J, Pien' kowski T, Semiglazova T, Stamatovic L, Timcheva C, Vasovic C, Vrbanec D, Zabore P, Delays in diagnosis and treatment of breast cancer: a multinational analysis, European Journal of Public Health, Vol. 24, No. 5, 761-767.

[16] Cui Y, Whiteman M, Laws A F J, Angenberg P, Kaczuk H T K, Bush T (2002) Body Mass And Stage Of Breast Cancer At Diagnosis 1nt. J. Cancer: 98, 279-28 (2002)(C2002WileyLiss, Inc. DOI10. 1002/ijc. 10209

[17] Lipscomb J, Fleming ST, Trentham-Dietz A, Kimmick G, Wu XC, Morris CR, Zhang K, Smith RA, Anderson RT, Sabatino SA; What Predicts an Advanced-Stage Diagnosis of Breast Cancer? Sorting Out the Influence of Method of Detection, Access to Care, and Biologic Factors. Centers for Disease Control and Prevention National Program of Cancer Registries Patterns of Care Study Group.

[18] Popoola A. O., Ibrahim N. A., Omodele F. O., Oludara M. A., Adebowale S. A., Igwilo A. I. (2012) Pattern of Spread of Breast Cancer among Patients attending Cancer Unit of Lagos State University Teaching Hospital. Asian Journal of Medical Science 4(3):89-94. 